\title{
EL SISTEMA DE EVALUACIÓN DE LA ACTIVIDAD INVESTIGADORA DE PROFESORES UNIVERSITARIOS
}

\author{
Antonio Jesús SÁNCHEZ RODRÍGUEZ \\ ABOGADO \\ DOCTOR EN DERECHO Y EN CIENCIAS POLÍTICAS
}

SUMARIO: I. General. Estatuto jurídico público del profesorado universitario. II. El Real Decreto 1086/1989, de 28 de agosto, sobre retribuciones del profesorado y normativa de desarrollo. II.1. Procedimiento de evaluación individualizada. II.2. La CNEAI y los Comités Asesores. II.3. La fijación de criterios para la evaluación. III. Los «especialistas» que han de ayudar a la CNEAI a enjuiciar la labor docente e investigadora del solicitante. IV. Motivación necesaria de las decisiones de la CNEAI. IV.1. Introducción. IV.2. Lo que ha dicho el TC sobre la motivación. IV.3. Control jurisdiccional de los actos administrativos dictados con apoyo en asesoramiento técnico. IV.4. IV.5. IV.6. IV.7. IV.8. IV.9. Alcance y contenido del informe emitido por el Comité Asesor. V. Algunas conclusiones.

RESUMEN: Originariamente la jurisprudencia entendió que la discrecionalidad técnica ejercida por órganos administrativos especializados no era susceptible de control jurídico debido a que dichos órganos asesores se limitarían a constatar las cualidades o datos que han de realizarse mediante valoraciones guiadas por los parámetros o criterios que son propios de un saber especializado no jurídico. No obstante, sí serían susceptibles de control jurídico todos aquellos elementos reglados de dichos procesos. En particular, en el caso de la valoración de la actividad investigadora de los profesores universitarios que realiza la Comisión Nacional de Evaluación de la Actividad Investigadora (CNEAI), la jurisprudencia ha establecido los límites de dicha discrecionalidad mediante la necesidad de motivar el juicio técnico, aun cuando la CNEAI se ampare en los comités de expertos. Es un caso interesante que nos sirve para explicar los límites de la discrecionalidad técnica en la actuación administrativa.

Palabras Clave: Sexenios, motivación de los actos administrativos, funcionarios de carrera, profesorado universitario

AbSTRACT: As originally established in the law, the technical discretion exercised by specialized administrative bodies was not subject to complete legal control due to these advisory bodies would be only limited to ascertain the qualities or data to be carried by parameters or criteria. However, regulated elements of these processes could be susceptible to legal control. There is an interesting case that explains quite well how to control the technical discretion of the specialized administrative bodies: the evaluation by the CNEAI of the research activity carried out by university professors. The case-law has set the limits of the technical discretion by the need of motivating the technical judgment, even if the CNEAI has been helped by expert committees. This motivation implies the disclosure of the legal and factual basis (justification) and of the reasons for adopting the administrative act.

KEYWORDS: "Sexenios", motivation of administrative acts, civil servants, professors of the university 


\section{General. Estatuto jurídico público del profesorado universitario}

El profesorado universitario, en cuanto funcionarios públicos, cuenta con un régimen jurídico estatutario peculiar, que nace de la Ley Orgánica 4/2007, de I2 de abril, por la que se modifica la Ley Orgánica 6/200I, de 2I de diciembre, de Universidades. Está integrado por los funcionarios de los cuerpos docentes universitarios y el personal contratado, que no puede superar nunca el 40 por too del total del personal docente e investigador de cada universidad.

La Ley Orgánica 4/2007, de I2 de abril, encomendó al Gobierno la elaboración de un Real Decreto sobre el estatuto del personal docente o investigador. Así, en la Disposición Adicional sexta señala que el estatuto del personal docente e investigador incluirá: (I) la regulación de una estructura de carrera funcionarial basada en la obtención de méritos; (2) la regulación de las condiciones para la gestión de la explotación de los resultados de la investigación; y (3) la regulación de la excedencia por incorporación a empresa de base tecnológica.

Esta especialidad dentro del régimen estatutario de los funcionarios ha conllevado en la práctica la profusión de normativa, en ocasiones dispersa, cuando no directamente contradictoria, o al menos que genera inseguridad jurídica pues se mantienen normas reglamentarias dictadas al amparo de Leyes que han sido sustituidas o modificadas. Así, a modo de ejemplo, sigue vigente la regulación del régimen del profesorado universitario según el Real Decreto 898/1985, de 30 de abril, sobre régimen del profesorado universitario, dictado en desarrollo de la Ley Orgánica II/I983, de 25 de agosto. Son también de aplicación el Real Decreto I3I2/2007, de 5 de octubre, por el que se establece la acreditación nacional del profesorado; el Real Decreto 1313/2007, de 5 de octubre, por el que se regula el régimen de los concursos de acceso del profesorado acreditado; el Real Decreto I393/2007 de 29 de octubre, por el que se establece la ordenación de las enseñanzas universitarias oficiales; y, finalmente, a modo de normativa general en todo lo no regulado por la normativa especial, la Ley 7/2007, de I2 de abril, del Estatuto Básico del Empleado Público y su texto refundido, el Real Decreto Legislativo 5/2015, de 30 de octubre, por el que se aprueba el texto refundido de la Ley del Estatuto Básico del Empleado Público.

A todo lo anterior habrá que añadir la normativa autonómica en aquellas Comunidades Autónomas que la hayan asumido y por tanto tengan competencia de desarrollo legislativo y ejecución de la enseñanza en toda su extensión, niveles y grados, modalidades y especialidades, de acuerdo con lo dispuesto en el art. 27 de la Constitución y en las Leyes Orgánicas que conforme al apartado I del art. 8i de la misma lo desarrollen, y sin perjuicio de las facultades que atribuye al Estado el número 30 del apartado I del art. I49 y de la alta inspección para su cumplimiento y garantía. La actual regulación universitaria, constituida por la Ley Orgánica 6/200I, de 2I de diciembre, contempla como competencias de las Comunidades Autónomas, entre otras, la regulación del régimen jurídico y retributivo del profesorado contratado, la capacidad para establecer retribuciones adicionales para el profesorado, la aprobación de programas de financiación plurianual conducentes a contratos-programa y la evaluación de la calidad de las universidades de su ámbito de responsabilidad'.

I La Ley Orgánica 6/200I, de 2I de diciembre, de Universidades, reconoce a las universidades públicas la posibilidad de contratar personal docente e investigador en régimen laboral. Dicho régimen laboral es 
En este trabajo vamos a tratar un aspecto específico del estatuto jurídico del profesorado universitario que tiene la condición de funcionario de carrera y según la normativa básica estatal: el sistema de evaluación de la actividad investigadora a efectos de determinar el complemento de productividad, conocida convencionalmente como «los sexenios», retribución complementaria que se abona al personal docente funcionario de carrera, que ha tenido un tratamiento amplio por la jurisprudencia, y que afecta al estatuto jurídico de este personal funcionario. Nos centramos en la potestad discrecional que tienen los órganos creados para la valoración de los méritos presentados al efecto, según ha sido definida por la jurisprudencia, que ha elaborado una explicación del alcance y límites de dicha potestad discrecional que se puede resumir en lo siguiente: dada la presumible imparcialidad de sus componentes, la especialización de sus conocimientos y la intervención directa en las pruebas realizadas, sus juicios técnicos no son susceptibles de control jurídico por la jurisdicción, y corresponden en exclusiva a aquellos órganos, sin que los Juzgados y Tribunales puedan subrogar en el lugar de dicho organismo ni pueda sustituirla. Todo esto es cierto, pero con muchos matices.

\section{El Real Decreto I086/1989, de 28 de agosto, sobre retribuciones del profesorado y normativa de desarrollo}

\section{II.I. Procedimiento de evaluación individualizada}

La evaluación de la actividad científica es un proceso reglado por distintas normas y Resoluciones. El sistema de evaluación de la actividad investigadora del personal docente universitario a efectos de determinar el complemento de productividad tiene su origen en el Real Decreto I086/1989, de 28 de agosto, sobre retribuciones del profesorado, que establece un mecanismo incentivador de la labor docente e investigadora del personal docente universitario (convencionalmente conocido como «PDI»). El sistema está basado en la evaluación individualizada de estas actividades en períodos de seis años, de cuyo resultado positivo se consigue la asignación del complemento de productividad. A estos efectos, los PDI son los funcionarios de carrera de los cuerpos docentes universitarios y de las escalas de Profesores de Investigación, Investigadores Científicos y Científicos Titulares del Consejo Superior de Investigaciones Científicas (CSIC).

En su art. 2.4 el Real Decreto Io86/1989, de 28 de agosto, establece que «el profesorado universitario podrá someter la actividad investigadora realizada cada seis años

configurado como una relación laboral de carácter especial, habilitando a las comunidades autónomas, en el ámbito de sus competencias, para regular y desarrollar su régimen jurídico, así como su régimen retributivo ordinario, y la posibilidad de establecer retribuciones adicionales ligadas a méritos de docencia, investigación y de gestión, tanto para esta clase de profesorado contratado como para el personal docente e investigador perteneciente a los cuerpos docentes universitarios. El artículo 48.I de la Ley Orgánica 6/200I, de 2I de diciembre establece que, en los términos de dicha Ley y en el marco de sus competencias, las Comunidades Autónomas establecerán el régimen del personal docente e investigador contratado de las Universidades. Por su parte, el art. 55.I, sobre retribuciones del personal docente e investigador contratado, añade que las Comunidades Autónomas regularán el régimen retributivo del personal docente e investigador contratado en las universidades públicas y el art. 55.2, además, permite establecer retribuciones adicionales ligadas a méritos individuales docentes, investigadores y de gestión. En suma, las Comunidades Autónomas tienen capacidad normativa específica en relación con la evaluación del profesorado (determinante para la contratación bajo determinadas modalidades y para la obtención de los complementos retributivos autonómicos), ámbito en el que la Ley Orgánica 6/200I, de 2I de diciembre, les atribuye competencia a partir de la remisión a los órganos de evaluación externa que la Comunidad Autónoma determine legalmente. 
en régimen de dedicación a tiempo completo a una evaluación, en la que se juzgará el rendimiento de la labor investigadora desarrollada durante el periodo».

\section{II.2. La CNEAI y los Comités Asesores}

La indicada valoración se encomienda a la Comisión Nacional Evaluadora de la Actividad Investigadora del Profesorado Universitario (CNEAI), integrada por representantes del Ministerio de Educación y Ciencia y de las Comunidades Autónomas con competencias asumidas en materia educativa, la cual podrá recabar el oportuno asesoramiento de miembros relevantes de la comunidad científica nacional e internacional cuya especialidad se corresponda con el área investigadora de los solicitantes, comportando la evaluación positiva la asignación de un complemento de productividad por un periodo de seis años. La CNEAI es, pues, el órgano al que corresponde efectuar la evaluación de la actividad investigadora de los profesores universitarios y del personal investigador del CSIC.

De acuerdo con la previsión reglamentaria, la Orden de 28 de diciembre de i989 constituyó la CNEAI, presidida por el Director General de Investigación Científica y Técnica, e integrada, además, por siete representantes del Ministerio de Educación y Ciencia, designados por el Secretario de Estado de Universidades e Investigación y uno designado por cada una de las Comunidades Autónomas con competencias en materia universitaria.

La evaluación se lleva a cabo anualmente y, para obtener el complemento de productividad, los investigadores han de someter a evaluación los trabajos científicos realizados durante un periodo no inferior a seis años.

Para la realización de las evaluaciones, la CNEAI cuenta con Comités Asesores, formados por expertos que efectúan el estudio técnico de los expedientes. La CNEAI puede nombrar también a otros expertos para actuar en áreas específicas o para otros cometidos.

\section{II.3. La fijación de criterios para la evaluación}

Las Órdenes de 5 de febrero de 1990 y I3 de diciembre de 1993 fijaron el procedimiento para la evaluación de la actividad investigadora, estableciendo los principios generales que habían de presidirla (calidad, creatividad, originalidad, aportación al conocimiento, capacidad de estimulación en el entorno, con ponderación de la situación general y de las circunstancias de la investigación científica española en cada periodo), así como los cinco criterios específicos de evaluación: dos criterios básicos (tipo Bi y tipo B2) y tres complementarios (tipos $\mathrm{C}_{1}, \mathrm{C}_{2}$ y $\mathrm{C}_{3}$ ), reiterando la potestad que ostenta la CNEAI de recabar el oportuno asesoramiento de miembros relevantes de la comunidad científica, articulándolo a través de los Comités Asesores por campos científicos, que emitirían para cada tramo oportuno, tras el examen del currículum aportado por el solicitante, informe valorando el conjunto de las aportaciones en cada uno de los cinco criterios específicos de evaluación de cero a diez puntos, siendo preciso alcanzar un mínimo de seis puntos para obtener una valoración positiva en el criterio correspondiente. Por fin, la CNEAI, a la vista de los informes emitidos por los Comités Asesores, procedería a la evaluación individual, asegurando, en todo caso, la aplicación de los principios más arriba reseñados (calidad, 
creatividad, originalidad, aportación al conocimiento, capacidad de estimulación en el entorno).

Los criterios de calidad que sirven de base para la evaluación están establecidos por una Orden del Ministerio de Educación y Ciencia, para el profesorado universitario, en concreto la Orden de 2 de diciembre de I994 y por una Resolución del Secretario de Estado de Universidades e Investigación para los investigadores del Consejo Superior de Investigaciones Científicas, en concreto la Resolución de 5 de diciembre de I994. La aplicación de los criterios de evaluación, establecidos en las disposiciones antes mencionadas, se realiza a través de comités asesores y expertos especialistas.

La Orden de 2 de diciembre de 1994 estableció algunas variaciones de criterios y denominación de criterios, como son el hecho de que entre los principios generales que deben observarse en la evaluación se encuentran que lo que se valorará es la contribución al progreso del conocimiento, la innovación y la creatividad de las aportaciones incluidas en el currículum vitae abreviado considerando la situación general de la ciencia en España y las circunstancias de investigación española en la disciplina correspondiente a cada evaluado y en el periodo a que corresponda la evaluación, así como la primacía de los trabajos formalmente científicos o innovadores frente a los descriptivos o de carácter divulgativo. ${ }^{2}$

Dicha Orden de I994 fue modificada por la Orden CIN/3040/2008, de 20 de octubre, por la que se modifica la Orden de 2 de diciembre de I994, por la que se establece el procedimiento para la evaluación de la actividad investigadora, en desarrollo del Real Decreto I086/1989, de 28 de agosto, sobre retribuciones del profesorado universitario. En el art. 8 de la Orden CIN/3040/2008, de 20 de octubre la indicación expresa -a que por otra parte hizo alusión la STS de 5 de julio de I996- de que «(p)ara la motivación de la Resolución que dicte la Comisión Nacional Evaluadora de la Actividad Investigadora bastará con la inclusión de los informes emitidos por los Comités Asesores y en su caso los especialistas si los mismos hubiesen sido asumidas por la Comisión Nacional. En caso contrario, deberán incorporarse a la Resolución de la Comisión Nacional los motivos que la

\footnotetext{
${ }^{2}$ Esta norma dispone en su art. 7.I que: En la evaluación se observará los siguientes principios generales: «a) Se valorará la contribución al progreso del conocimiento, la innovación y creatividad de las aportaciones incluidas en el currículum abreviado, considerando la situación general de la ciencia en España y las circunstancias de la investigación española en la disciplina correspondiente a cada evaluado y en el periodo al que corresponda la evaluación. b) Se primarán los trabajos formalmente científicos o innovadores frente a los meramente descriptivos, a los que sean simple aplicación de los conocimientos establecidos o a los de carácter divulgativo. Éstos últimos sólo podrán llegar a tener valor complementario, salvo en circunstancias especiales apreciadas por el órgano evaluador.» Y en su art. 8: «I. Los Comités asesores y, en su caso, los especialistas consultados deberán formular un juicio técnico sobre la obra aportada por el solicitante en el currículum vitae abreviado, dentro del contexto definido por el currículum vitae completo. 2. El juicio técnico se expresará en términos numéricos de cero a Io, siendo preciso un mínimo de seis puntos para obtener una evaluación positiva en un tramo de seis años. En el caso de las evaluaciones únicas a las que se refiere el art. II de esta Orden el juicio técnico se expresará en términos numéricos de cero hasta el número que resulte de multiplicar por io el número de tramos solicitados. 3. La Comisión Nacional establecerá la evaluación individual definitiva, a la vista de las calificaciones emitidas por los Comités asesores y los especialistas, asegurando, en todo caso, la aplicación de los principios generales establecidos en el artículo séptimo de esta Orden. En las evaluaciones consideradas en el art. II de esta Orden el número de tramos evaluados positivamente será igual al número entero que resulte de dividir por seis la puntuación total asignada. Para la motivación de la resolución que dicte la Comisión Nacional Evaluadora de la Actividad Investigadora bastará con la inclusión de los informes emitidos por los Comités asesores y, en su caso, los especialistas, si los mismos hubiesen sido asumidas por la Comisión Nacional. En caso contrario deberán incorporarse a la resolución de la Comisión Nacional los motivos que la han llevado a apartarse de los referidos informes, así como la fundamentación, avalada o no por otros informes dictados por especialistas, de la decisión final.»
} 
han llevado a apartarse de los referidos informes, así como la fundamentación, avalada o no por otros informes dictados por especialistas en la decisión final».

En desarrollo de esta Orden se dictó la Resolución de 12 de noviembre de 2008, de la Secretaría de Estado de Universidades, por la que se fija el procedimiento y plazo de presentación de solicitudes de evaluación de la actividad investigadora a la CNEAI. La Orden ECD/2713/2003, de 26 de septiembre, aprueba el Reglamento de Funcionamiento Interno de la CNEAI.

Finalmente, la Resolución de I5 de noviembre de 2013, de la CNEAI publica los criterios específicos aprobados para cada uno de los campos de evaluación. Así mismo, la Resolución de 26 de noviembre de 20I4, de la CNEAI, se publican los criterios específicos aprobados para cada uno de los campos de evaluación, y la Resolución de 2I de noviembre de 2013, de la Secretaría de Estado de Educación, Formación Profesional y Universidades, fija el procedimiento y plazo de presentación de solicitudes de evaluación de la actividad investigadora a la CNEAI.

\section{Los «especialistas» que han de ayudar a la CNEAI a enjuiciar la labor docente e investigadora del solicitante}

El art. I2 de la Orden ECI/27I3/2003, de 26 de septiembre, establece lo siguiente:

«Art. I2. Otros especialistas.

I. Cuando la especificidad de un área de conocimiento determinada o de la actividad investigadora sometida a evaluación lo haga aconsejable, la CNEAI podrá recabar, además, el asesoramiento de otros especialistas vinculados con esa área o actividad específica.

2. Corresponde a los especialistas asistir a los Comités asesores en su labor de evaluación. La asistencia deberá quedar circunscrita al área de su especialidad.

3. Los informes emitidos por los especialistas tendrán carácter subsidiario respecto de los juicios técnicos emitidos por los Comités Asesores.»

Por tanto, es común que para realizar esta evaluación se acuda a estos asesores «especialistas» en la concreta materia («área o actividad específica»), suscitando entonces interesantes interrogantes jurídicos. Los referidos asesores han de pertenecer a las áreas de conocimiento» enjuiciado.

El art. I3.2 de la Orden ECD/2713/2003, de 26 de septiembre, indica que «(t)anto el listado completo de los miembros que componen cada Comité Asesor, como el nombramiento de especialistas, deberá ser publicado en el Boletín Oficial del Estado»; lo que ya había sido establecido por la Orden de I6 de noviembre de 2000 , por la que se actualiza la de 2 de diciembre de I994, que indica en su apartado 2 del art. 3 que «[...] 2. La denominación de las plazas de la plantilla de profesorado funcionario será necesariamente la de alguna de las áreas de conocimiento a que hace referencia la disposición transitoria primera del presente Real Decreto. A tales efectos se entenderá por área de conocimiento aquellos campos del saber caracterizados por la homogeneidad de su objeto de conocimiento, una común tradición histórica y la existencia de comunidades de investigadores, nacionales o internacionales». 
La decisión de este Comité Asesor viene a ser fundamental en la final resolución por la Comisión. El Comité, al igual que la propia CNEAI, goza de discrecionalidad técnica en el desarrollo de su contenido de valoración ${ }^{3}$. Hasta aquí nada nuevo, pues según consolidada doctrina del Tribunal Constitucional, que ha hecho suya, a su vez, una también consolidada doctrina jurisprudencial (entre otras, las SsTS de 22 de octubre de I973, y de 28 de marzo de i987, que establece que aunque los tribunales de la jurisdicción contenciosoadministrativa, y en lo que a esta materia afecta, los sistemas de revisión de los actos administrativos por parte de la propia Administración, son ciertamente competentes para enjuiciar la legalidad de la actuación de los órganos encargados de realizar valoraciones en las que interviene la discrecionalidad, en modo alguno pueden sustituir a éstos en lo que sus valoraciones tienen de apreciación técnica, puesto que se trata de cuestiones que deben valorarse en función de parámetros no jurídicos. Es decir, aunque el acto administrativo de calificación pueda ser objeto de la acción fiscalizadora de los tribunales, la revisión encuentra límites que se fundamentan en una presunción de razonabilidad o de certeza de la actuación administrativa, apoyada en la especialización y la imparcialidad de los órganos establecidos para efectuar la calificación. Ahora bien, dicha presunción es iuris tantum, es decir, admite prueba en contrario, por lo que puede desvirtuarse si se acredita fehacientemente que en el órgano calificador no concurre cualquiera de las dos circunstancias en que se fundamental dicha presunción: especialización e imparcialidad, por ser su actuación arbitraria, absolutamente injustificada o constitutiva de desviación de poder ${ }^{4}$.

En efecto, sobre el ámbito del posible control jurisdiccional de la discrecionalidad técnica de que gozan los tribunales calificadores de concursos y oposiciones, la STC 34/I995, de 6 de febrero, decía que «(l)a primera observación que hay que hacer es que el reconocimiento de la sumisión de la Administración a la Ley y al Derecho, que la Constitución eleva a núcleo central que preside el obrar administrativo (art. IO3.I CE), equivale a una prohibición generalizada de áreas de inmunidad en esta parcela del ordenamiento jurídico, conectándose de este modo la garantía de sumisión a la norma con la interdicción de arbitrariedad en el obrar de los poderes públicos (art. 9) y la primacía de la Ley, como postulado básico de un Estado de Derecho (art. I CE). Corolario inevitable de este marco normativo en que la Constitución encaja la actuación administrativa es, a su vez, la sujeción de los actos de ésta al control de los Tribunales de Justicia (art. I06.I CE). Siendo los anteriores preceptos los presupuestos de la declaración contenida en el art. Io6.I CE, es claro que estamos ante un diseño constitucional de control máximo de la actividad administrativa, en la que, salvo exclusión legal expresa y fundada en motivos suficientes no se produzcan exenciones en la regla general de sujeción de aquélla al control y fiscalización de los Tribunales de Justicia. Que esto es así se desprende de una jurisprudencia reiterada, que se ha ocupado de mantener que si bien la Constitución no ha definido cuáles han de ser «los instrumentos procesales que hagan posible ese control jurisdiccional», sí ha

\footnotetext{
${ }^{3}$ Sobre la discrecionalidad técnica en los procesos de selección y valoración de los funcionarios públicos, vid. más ampliamente, ParadA, R.; FuentetAjA, J.: Derecho de la Función Pública, Madrid, Open ediciones universitarias, 20I5, págs. 234 y sigs. También Alegre ÁvilA, J.M.: «Objetividad e imparcialidad de la Administración: el principio de especialidad en la composición de los órganos de selección», Revista Vasca de Administración Pública, núm. 34, I992, págs.. 9-37; DesDentAdo DAROCA, E.: «Los problemas del control judicial de la discrecionalidad técnica (Un estudio crítico de la jurisprudencia)», Madrid, Civitas, I997; CHINCHILLA, C., Lozano, B., y Del SAZ, S.: Nuevas perspectivas del Derecho Administrativo. Tres estudios, Madrid, Civitas, I992.

${ }^{4}$ Cfr. AaTS 274/ı983 y 681/i986 y SsTS 39/1983, 97/1993, 353/1993 y 34/1995, etc.
} 
afirmado, en cambio, la necesidad de que dichos mecanismos «han de articularse de tal modo que aseguren, sin inmunidades de poder, una fiscalización plena del ejercicio de las atribuciones administrativas».

Todo lo anterior, trasladado al caso que nos ocupa (la especialización de los expertos que hacen las calificaciones del personal docente e investigador), nos lleva a considerar que los expertos deban acreditar un conocimiento suficiente para juzgar un itinerario centrado en los proyectos de investigación presentados por el funcionario a calificar. Es ahí donde surgen los conflictos entre la Administración que valora y el funcionario, dando lugar a una interesante jurisprudencia.

\section{Motivación necesaria de las decisiones de la CNEAI}

\section{IV.I. Introducción}

La jurisprudencia procedente del TS y del TC ha estado caracterizada por el permanente esfuerzo de ampliar al máximo y perfeccionar el control jurisdiccional previsto constitucionalmente frente a toda actuación administrativa (art. Io6.I CE), y sus líneas maestras e hitos evolutivos se pueden resumir en lo que sigue.

La legitimidad de lo que doctrinalmente se conoce como discrecionalidad técnica fue objeto de reconocimiento por la STC 39/1983, de I6 de mayo, que justificó y explicó su alcance respecto al control jurisdiccional con esta declaración: «Pero no puede olvidarse tampoco que ese control puede encontrar en algunos casos límite determinados. Así ocurre en cuestiones que han de resolverse por un juicio fundado en elementos de carácter exclusivamente técnico, que sólo puede ser formulado por un órgano especializado de la Administración y que en sí mismo escapa por su propia naturaleza al control jurídico, que es el único que pueden ejercer los órganos jurisdiccionales, y que, naturalmente, deberán ejercerlo en la medida en que el juicio afecte al marco legal en que se encuadra, es decir, sobre las cuestiones de legalidad, (...)».

La jurisprudencia inicial, desde el mismo momento del reconocimiento de esa discrecionalidad técnica, ya se preocupó en señalar unos límites para la misma, que vinieron a consistir en la aplicación también a ella de las técnicas de control que significan los elementos reglados, los hechos determinantes y los principios generales del derecho. Así lo hizo la STS de 5 de octubre de I989, que se expresa así: «Los órganos administrativos a quienes corresponde la valoración de las pruebas de acceso a la función pública gozan de un cierto margen de discrecionalidad en la apreciación de las pruebas, que incluso merece la calificación de técnica no revisable jurisdiccionalmente en lo que se refiere a los juicios que la Administración emita acerca de la apreciación de los méritos aportados o ejercicios realizados, pero ello no excluye el que los Tribunales puedan controlar la concurrencia de los límites generales jurídicamente impuestos a la actividad discrecional no técnica de la Administración que se refieren a la competencia del órgano, procedimiento, hechos determinantes, adecuación al fin perseguido y al juego de los principios generales del derecho, entre los que, en estos casos, cobran especial interés los de mérito y capacidad expresamente señalados al efecto por el artículo I03 CE».

La evolución jurisprudencial posterior, en aras de perfeccionar el control jurisdiccional y definir los espacios donde este control puede operar con normalidad, 
completó y aclaró esos límites inicialmente enunciados mediante la distinción, dentro de la actuación de valoración técnica, entre el «núcleo material de la decisión» y sus «aledaños». El primero estaría representado por el estricto dictamen o juicio de valor técnico, y los segundos (los aledaños) comprenderían, de un lado, las actividades preparatorias o instrumentales que rodean a ese estricto juicio técnico para hacerlo posible y, de otro, las pautas jurídicas que también son exigibles a dichas actividades.

Esas actividades preparatorias o instrumentales serían las encaminadas a delimitar la materia que vaya a ser objeto de ese juicio técnico, a fijar los criterios de calificación que vayan a ser utilizados y a aplicar individualizadamente dichos criterios a cada uno de los elementos materiales que constituyan el objeto de la valoración; esto es, serían los pasos que resultan necesarios para llegar a la estimación cualitativa finalmente contenida en el estricto juicio técnico.

Y esas pautas jurídicas estarían identificadas por el derecho a la igualdad de condiciones que asiste a todos los aspirantes, por la necesidad de que el criterio de calificación responda a los principios de mérito y capacidad y por el obligado cumplimiento también del mandato constitucional de interdicción de la arbitrariedad ${ }^{5}$.

Un punto más en esa línea evolutiva de la jurisprudencia lo representa la necesidad de motivar el juicio técnico.

En efecto, como ya se ha puesto de manifiesto, uno de los aledaños de ese juicio técnico está representado por la obligación de cumplir el mandato constitucional ( artículo 9.3 CE ) de la interdicción de la arbitrariedad de los poderes públicos y, en el criterio de este Tribunal Supremo, ese cumplimiento conlleva la necesidad de motivar el juicio cuando así sea solicitado por algún aspirante o cuando sea objeto de impugnación. ${ }^{6}$

La fase final de la evolución jurisprudencial la constituye la definición de cuál debe ser el contenido de la motivación para que, cuando sea exigible, pueda ser considerada válidamente realizada. A este respecto se ha declarado que ese contenido debe cumplir al menos estas principales exigencias: (I) expresar el material o las fuentes de información sobre las que va a operar el juicio técnico; (2) consignar los criterios de valoración cualitativa que se utilizarán para emitir el juicio técnico; y (3) expresar por qué la aplicación de esos

${ }^{5}$ Esta distinción está presente en la STC 215/199I, de I4 de noviembre, como también en numerosas sentencias de esta Sala (entre otras, en las SSTS de 28 de enero de I992, recurso I72671990; de in de diciembre de I995 recurso I3272/I99I; I5 de enero de I996, recurso 7895/I99I; y i de julio de I996, recurso 7904/I990).

${ }^{6}$ Así se expresa STS de io de mayo de 2007, recurso 545/2002: «(...) Tiene razón el recurso de casación en que la sentencia de instancia no enjuició correctamente la cuestión de fondo que le fue suscitada y en la infracción del artículo 24 de la Constitución que con ese argumento se denuncia. La doctrina de la discrecionalidad técnica con que la Sala de Zaragoza justifica principalmente su pronunciamiento no ha sido correctamente aplicada; y no lo ha sido porque, en relación a la actuación administrativa para la que se ha hecho esa aplicación, no se ha observado el límite constitucional de interdicción de la arbitrariedad de los poderes públicos (artículo 9.3 CE). Como es bien sabido, dicha discrecionalidad técnica significa, por un lado, respetar las valoraciones de esa índole que hayan sido realizadas por los órganos cualificados por la posesión del correspondiente saber especializado y, por otro, admitir el margen de polémica o discrepancia que sobre determinadas cuestiones venga siendo tolerado en el concreto sector de conocimientos técnicos de que se trate. Pero una cosa es el núcleo del juicio técnico sobre el que opera esa clase de discrecionalidad y otra diferente la obligación de explicar las razones de ese juicio técnico cuando expresamente hayan sido demandadas o cuando se haya planteado la revisión de la calificación que exteriorice ese juicio técnico. Esto último queda fuera del ámbito propio del llamado juicio de discrecionalidad técnica, ya que, ante la expresa petición de que dicho juicio sea explicado o ante su revisión, la constitucional prohibición de arbitrariedad hace intolerable el silencio sobre las razones que hayan conducido a emitir el concreto juicio de que se trate». 
criterios conduce al resultado individualizado que otorga la preferencia a un candidato frente a los demás.

Son exponente de este último criterio jurisprudencial los pronunciamientos del TS sobre nombramientos de altos cargos jurisdiccionales (STS de 27 de noviembre de 2007 , recurso 407/2006), sobre concursos de personal docente universitario (STS de i9 de mayo de 2008, recurso 4049/2004), sobre convocatorias del Consejo General del Poder Judicial para puestos en sus órganos técnicos (STS de io de octubre de 2007, recurso 337/2004); o sobre procesos selectivos en las distintas Administraciones Públicas (STS de I8 de diciembre de 2013, casación 3760/2012).

IV.2. Lo que ha dicho el TC sobre la motivación

El TC ha tenido ocasiones varias para analizar la motivación de los actos administrativos. Su línea jurisprudencial se puede resumir en lo siguiente: (I) La motivación es esencial para exteriorizar el fundamento jurídico de la decisión y para permitir su control, pero no es necesario que sea exhaustiva mientras permita esas dos finalidades (STC I50/1988). (2) La utilización de formularios o modelos es correcta si con esa respuesta genérica se da adecuada respuesta al problema planteado, permitiendo conocer las razones de la decisión ( STC 72/1990). (3) Cabe la motivación por remisión al expediente y a informes (SsTC I74/87, I46/90) precisando el TS que «En el derecho positivo español la motivación puede recogerse en el propio acto, o puede encontrarse en los informes o dictámenes previos cuando el acto administrativo se produzca de conformidad con los mismos que queden incorporados a la resolución» (STS I63/2002). Y (4) Requerir la motivación del acto administrativo discrecional es, también, garantía de la interdicción de la arbitrariedad del poder público y su control no es tarea ajena a la función jurisdiccional (art. I06.I CE).

En definitiva, la Administración ha de estar en todo momento en condiciones de explicar que no ha ejercido de forma arbitraria sus facultades discrecionales, de modo más riguroso si su actuación afecta a los derechos fundamentales, libertades públicas y valores constitucionales (STC I63/2002).

IV.3. Control jurisdiccional de los actos administrativos dictados con apoyo en asesoramiento técnico

Hay, como decimos, suficiente y amplia jurisprudencia sobre la necesidad de que las decisiones de la CNEAI estén debidamente motivadas, dentro de las dificultades que ello entraña, habiéndose expresando con carácter reiterado la trascendencia de la omisión de este requisito por cuanto la existencia (y razonabilidad) del juicio valorativo, motivación o fundamentación de la decisión en cuestión pasa a constituirse en elemento esencial del control jurisdiccional de la actuación administrativa.

Como sabemos, la motivación es elemento diferenciador entre discrecionalidad y arbitrariedad, cuya finalidad es dar a conocer a los administrados las razones de la decisión adoptada, asegurando la seriedad en la formación de la voluntad de la Administración y posibilitando la impugnación por el interesado del acto administrativo de que se trata, criticando sus bases y facilitando el control jurisdiccional, resultando tan trascendente el 
requisito en cuestión que será nulo el acto administrativo que se apoye en una valoración no debidamente concretada.

En este marco general, la doctrina del TS (por todas, STS de 22 de febrero de 2005) ha tenido ocasión, sin embargo, de introducir matices. Entre ellos se encuentra, por lo que ahora nos interesa, la legitimidad del respeto a la discrecionalidad técnica de los órganos de la Administración, en cuanto promueven y aplican criterios resultantes de los concretos conocimientos especializados, requeridos por la naturaleza de la actividad desplegada por el órgano administrativo. Con referencia a ella, se ha afirmado que, aun en estos supuestos, las modulaciones que encuentra la plenitud de conocimiento jurisdiccional sólo se justifican en una presunción de certeza o de razonabilidad de la actuación administrativa, apoyada en la especialización y la imparcialidad de los órganos establecidos para realizar la calificación. Una presunción iuris tantum, de ahí que siempre quepa desvirtuarla «si se acredita la infracción o el desconocimiento del proceder razonable que se presume en el órgano calificador, bien por desviación de poder, arbitrariedad o ausencia de toda posible justificación del criterio adoptado», entre otros motivos, por fundarse en patente error, debidamente acreditado por la parte que lo alega.

Tal criterio fue ratificado por la STC de io de mayo de 2004 , que subraya que «ni el artículo 24.I ni el 23.2 CE incorporan en su contenido un pretendido derecho de exclusión del control judicial de la llamada discrecionalidad técnica». Y es que «debe recordarse que, frente a la discrecionalidad técnica que ha de reconocerse a los órganos de selección en el marco de ese -prudente y razonable- arbitrio, nunca excesivo, las modulaciones que encuentra la plenitud de conocimiento jurisdiccional sólo se justifican en una presunción de certeza o de razonabilidad de la actuación administrativa, apoyada en la especialización y la imparcialidad de los órganos establecidos para realizar la calificación»?

\footnotetext{
${ }^{7}$ Por otro lado, ya la STS de 22 de febrero de 2005 , señaló lo siguiente, referido a los procesos de selección del personal, pero plenamente aplicables a nuestro caso de valoración de actividades de investigación: «a) En primer lugar, el art. 23.2 de la CE consagra un derecho a la predeterminación normativa del procedimiento de acceso a las funciones públicas. En este sentido, con carácter general la Constitución reserva a la Ley y, en todo caso, al principio de legalidad, entendido como existencia de norma jurídica previa, la regulación de las condiciones de ejercicio del derecho, lo que entraña una garantía de orden material que se traduce en la imperativa exigencia de predeterminar cuáles hayan de ser las condiciones para acceder a la función pública de conformidad con los principios constitucionales de igualdad, mérito y capacidad, que sólo pueden preservarse y, aun antes, establecerse mediante la intervención positiva del legislador, resultando esta exigencia más patente y de mayor rigor e intensidad en el caso de acceso a la función pública que cuando, dentro ya de la misma, se trata del desarrollo y promoción de la carrera administrativa. b) Desde esta perspectiva, se entiende que la preexistencia y predeterminación de las condiciones de acceso, aunque no pueda ser cuestionada automáticamente en este proceso, forma parte del derecho fundamental en cuanto constituye su soporte y puede ser aquí invocada cuando vaya inescindiblemente unida a la posible vulneración de las condiciones materiales de igualdad de mérito y capacidad. c) El derecho proclamado en el art. 23.2 CE incorpora el derecho a la igualdad en la aplicación de la Ley, de tal modo que durante el desarrollo del procedimiento selectivo ha de quedar excluida en la aplicación de las normas reguladoras del mismo toda diferencia de trato entre los aspirantes, habiendo de dispensárseles a todos un trato igual en las distintas fases del procedimiento selectivo, pues las condiciones de igualdad a las que se refiere el art. 23.2 CE se proyectan no sólo a las propias "leyes", sino también a su aplicación e interpretación. d) Por último, una reiterada doctrina jurisprudencial ha destacado el protagonismo que a los Jueces y Tribunales corresponde en el control de la regularidad del proceso selectivo, toda vez que al ser el derecho proclamado en el art. 23.2 CE un derecho de configuración legal, "corresponde a los órganos jurisdiccionales concretar en cada caso cuál es la normativa aplicable, pues es a ellos a quienes corresponde en exclusiva, de conformidad con el art. II7.3 CE, el enjuiciamiento de los hechos y la selección e interpretación de las normas" (SsTC ıo/ı989, de 24 de enero y 73/ı998, de 31 de marzo)». Así mismo, la STS de 6 de octubre de 20II, con cita de la de i8 de marzo de 20II, que sigue la exposición de la STS de i de abril de 2009, recoge la doctrina y evolución de la llamada discrecionalidad técnica.
} 
IV.4. La legitimidad de lo que doctrinalmente se conoce como discrecionalidad técnica fue objeto de reconocimiento por la STC 39/1983, de I6 de mayo

Posteriormente, la STS de 6 de octubre de 20 II justificó y explicó su alcance respecto al control jurisdiccional que había dado la STC 39/1983, con esta declaración: «Pero no puede olvidarse tampoco que ese control puede encontrar en algunos casos límites determinados. Así ocurre en cuestiones que han de resolverse por un juicio fundado en elementos de carácter exclusivamente técnico, que sólo puede ser formulado por un órgano especializado de la Administración y que en sí mismo escapa por su propia naturaleza al control jurídico, que es el único que pueden ejercer los órganos jurisdiccionales, y que, naturalmente, deberán ejercerlo en la medida en que el juicio afecte al marco legal en que se encuadra, es decir, sobre las cuestiones de legalidad, (...)».

IV.5. La jurisprudencia inicial del TS, desde el mismo momento del reconocimiento de esa discrecionalidad técnica, ya se preocupó en señalar unos límites para la misma, que vinieron a consistir en la aplicación también a ella de las técnicas de control que significan los elementos reglados, los hechos determinantes y los principios generales del derecho

Así lo hizo la STS de 5 de octubre de 1989, que se expresa así: «Los órganos administrativos a quienes corresponde la valoración de las pruebas de acceso a la función pública gozan de un cierto margen de discrecionalidad en la apreciación de las pruebas, que incluso merece la calificación de técnica no revisable jurisdiccionalmente en lo que se refiere a los juicios que la Administración emita acerca de la apreciación de los méritos aportados o ejercicios realizados, pero ello no excluye el que los Tribunales puedan controlar la concurrencia de los límites generales jurídicamente impuestos a la actividad discrecional no técnica de la Administración que se refieren a la competencia del órgano, procedimiento, hechos determinantes, adecuación al fin perseguido y al juego de los principios generales del derecho, entre los que, en estos casos, cobran especial interés los de mérito y capacidad expresamente señalados al efecto por el art. I03 CE».

IV.6. La evolución jurisprudencial posterior, en aras de perfeccionar el control jurisdiccional y definir los espacios donde este control puede operar con normalidad, completó y aclaró esos límites inicialmente enunciados mediante la distinción, dentro de la actuación de valoración técnica, entre el «núcleo material de la decisión» y sus «aledaños»

El primero estaría representado por el estricto dictamen o juicio de valor técnico, y los segundos (los aledaños) comprenderían, de un lado, las actividades preparatorias o instrumentales que rodean a ese estricto juicio técnico para hacerlo posible y, de otro, las pautas jurídicas que también son exigibles a dichas actividades.

Esas actividades preparatorias o instrumentales serían las encaminadas a delimitar la materia que vaya a ser objeto de ese juicio técnico, a fijar los criterios de calificación que vayan a ser utilizados y a aplicar de forma individual dichos criterios a cada uno de los elementos materiales que constituyan el objeto de la valoración; esto es, serían los pasos que resultan necesarios para llegar a la estimación cualitativa finalmente contenida en el 
estricto juicio técnico. Y esas pautas jurídicas estarían encarnadas por el derecho a la igualdad de condiciones que asiste a todos los aspirantes, por la necesidad de que el criterio de calificación responda a los principios de mérito y capacidad y por el obligado cumplimiento también del mandato constitucional de interdicción de la arbitrariedad.

La anterior distinción está presente en la STC 215/I99I, de I4 de noviembre, como también en numerosas sentencias del TS (entre otras, en las SsTS de 28 de enero de I992; de II de diciembre de I995; I5 de enero de I996; y i de julio de 1996, etc.). En todo caso, la interpretación que se haga, como establecen varias sentencias de tribunales superiores de justicia, por el contrario «ha de examinarse a la luz de la evolución normativa en cuanto a la intensificación de los requisitos de motivación de las resoluciones administrativas, y de la misma evolución de la jurisprudencia, en cuanto a la expansión del control jurisdiccional sobre la discrecionalidad técnica de los órganos de selección (en este caso, de evaluación» ${ }^{8}$.

IV.7. Un punto más en esa línea evolutiva de la jurisprudencia lo representa la necesidad de motivar el juicio técnico

Como ya se ha puesto de manifiesto, uno de los aledaños de ese juicio técnico está representado por la obligación de cumplir el mandato constitucional (art. 9.3 CE) de la interdicción de la arbitrariedad de los poderes públicos y, en el criterio del TS, ese cumplimiento conlleva la necesidad de motivar el juicio cuando así sea solicitado por algún aspirante o cuando sea objeto de impugnación, como ha ocurrido en el supuesto que ahora examinamos. ${ }^{9}$

Recuerda el TS que dicha discrecionalidad técnica significa, por un lado, respetar las valoraciones de esa índole que hayan sido realizadas por los órganos cualificados por la posesión del correspondiente saber especializado y, por otro, admitir el margen de polémica o discrepancia que sobre determinadas cuestiones venga siendo tolerado en el concreto sector de conocimientos técnicos de que se trate.

Pero una cosa es el núcleo del juicio técnico sobre el que opera esa clase de discrecionalidad y otra diferente la obligación de explicar las razones de ese juicio técnico cuando expresamente hayan sido demandadas o cuando se haya planteado la revisión de la

\footnotetext{
${ }^{8}$ Al respecto, FERnÁNDEZ-EsPinAR ha dicho lo siguiente: «Por todo ello, entendemos que son la propia administración y los poderes públicos quienes deben internalizar la exigencia de esta realidad jurídicoconstitucional y su preceptiva obligación de justificar y explicar los motivos de sus decisiones, fundamentándolas en informes y criterios objetivos y veraces. La discrecionalidad, como establece la jurisprudencia citada, ya no es un prius sino una «consecuencia del previo respeto a la legalidad», una mera opción, que no se tiene en los actos reglados, por la que la administración pueda decidir, en razón del interés general y solamente en base al mismo, entre varias opciones que deben respetar escrupulosamente la legalidad. Para ello, siguiendo el camino iniciado por prestigiosos autores citados en el presente trabajo, consideramos que el único y eficaz remedio es invertir la carga de la prueba y del dogma de la «presunción de legalidad del acto administrativo», siendo la administración quien tenga que acreditar y justificar previa y detalladamente el interés público de su decisión, la realidad de los hechos sobre los que va adoptar la decisión, el cumplimiento de todos los principios generales del derecho (igualdad, proporcionalidad, etc.) y del contenido de las normas aplicables en cada caso». En «El control judicial de la discrecionalidad administrativa. la necesaria revisión de la construcción dogmática del mito de la discrecionalidad y su control», Revista Jurídica de Castilla y León, n. 26, enero de 20I2, pág. 254 .

${ }^{9}$ Así se expresa la STS de io de mayo de 2007: «(...) Tiene razón el recurso de casación en que la sentencia de instancia no enjuició correctamente la cuestión de fondo que le fue suscitada y en la infracción del art. 24 de la Constitución que con ese argumento se denuncia.»
} 
calificación que exteriorice ese juicio técnico. Esto último queda fuera del ámbito propio del llamado «juicio de discrecionalidad técnica», ya que, ante la expresa petición de que dicho juicio sea explicado o ante su revisión, la constitucional prohibición de arbitrariedad hace intolerable el silencio sobre las razones que hayan conducido a emitir el concreto juicio de que se trate.

IV.8. La fase final de la evolución jurisprudencial la constituye la definición de cuál debe ser el contenido de la motivación para que, cuando sea exigible, pueda ser considerada válidamente realizada

$\mathrm{Y}$ a este respecto se ha declarado que ese contenido debe cumplir al menos estas principales exigencias: (I) expresar el material o las fuentes de información sobre las que va a operar el juicio técnico; (2) consignar los criterios de valoración cualitativa que se utilizarán para emitir el juicio técnico; y (3) expresar por qué la aplicación de esos criterios conduce al resultado individualizado que otorga la preferencia a un candidato frente a los demás.

Son exponente de este último criterio jurisprudencial los pronunciamientos del TS sobre nombramientos de altos cargos jurisdiccionales (STS de 27 de noviembre de 2007), sobre concursos de personal docente universitario (STS de i9 de mayo de 2008) y sobre convocatorias del Consejo General del Poder Judicial para puestos en sus órganos técnicos (STS de Io de octubre de 2007 ) y la propia STS de I de abril de 2009 relativa a proceso selectivo para el acceso al cuerpo de profesores de enseñanza secundaria («Los órganos administrativos a quienes corresponde la valoración de las pruebas de acceso a la función pública gozan de un cierto margen de discrecionalidad en la apreciación de las pruebas, que incluso merece la calificación de técnica no revisable jurisdiccionalmente en lo que se refiere a los juicios que la Administración emita acerca de la apreciación de los méritos aportados o ejercicios realizados, pero ello no excluye el que los Tribunales puedan controlar la concurrencia de los límites generales jurídicamente impuestos a la actividad discrecional no técnica de la Administración que se refieren a la competencia del órgano, procedimiento, hechos determinantes, adecuación al fin perseguido y al juego de los principios generales del derecho, entre los que, en estos casos, cobran especial interés los de mérito y capacidad expresamente señalados al efecto por el artículo I03 CE»). ${ }^{\text {Io }}$

\footnotetext{
${ }^{10}$ Dicha doctrina la reproduce la más reciente STS de I5 de diciembre de 20II, que señala lo siguiente: «La jurisprudencia del Tribunal Constitucional, desde las sentencias 39/1983, de I7 de mayo, y 353/1993, de 29 de noviembre y de este Tribunal Supremo [por todas, las sentencias de esta misma Sala de I3 de marzo de I99I, 20 de octubre de I992 (recurso 534/I989), 2 de octubre de 2000 (recurso 603/I998), I3 de octubre de 2004 (recurso 572/200I), 2I de mayo de 2008 (recurso 2I37/2004), I7 de junio de 2009 (recurso 6764/2005) y I3 de julio de 2OII (recurso 284/20Io)], han puesto de relieve que la revisión jurisdiccional, en cuanto a la valoración de los tribunales calificadores en lo que de apreciación técnica tenga en sí misma, escapa al control jurídico y se concreta en diferentes modulaciones, limitaciones o simples criterios interpretativos o de actuación que encuentran su fundamento jurídico en una presunción de razonabilidad y de certeza con respecto a la actuación administrativa, basada en la especialización y en la imparcialidad que debe presumirse, salvo prueba en contrario, en la actuación llevada a cabo por los órganos establecidos para proceder a la correspondiente calificación» y que «Tales órganos gozan, según la apuntada doctrina jurisprudencial, de discrecionalidad técnica, en función, precisamente, no sólo de las ya reflejadas imparcialidad y especialización de las comisiones de calificación y selección, sino también como consecuencia de su intervención directa en las mismas pruebas realizadas, no pudiendo los Tribunales de Justicia convertirse en segundos tribunales calificadores que revisen la totalidad de las pruebas selectivas que puedan llevarse a cabo, sustituyendo por sus criterios de calificación los que, a tenor de dicha discrecionalidad técnica, corresponden al tribunal juzgador del respectivo proceso selectivo», y tras distinguir conforme a su doctrina entre «los elementos reglados, los hechos determinantes y los principios generales del derecho; y subrayando también que la más reciente doctrina de esta Sala en aras de
} 
Por lo que se refiere más concretamente al ámbito de actuación de la CNEAI, la STS de 5 de julio de 1996 dictada en recurso de casación en interés de Ley interpuesto por el Abogado del Estado contra la Sentencia de fecha 3 de marzo de I994, de la Sala de lo Contencioso-Administrativo (Sección Sexta) del Tribunal Superior de Justicia de Madrid, dictada en el recurso I303/92 -que declaró no ajustada a Derecho la Resolución de la CNEAI de fecha 23 de noviembre de I990, por la que se valoró negativamente el tercer y cuarto tramos solicitados, y en la que, además de hacerse mención a la normativa y a los antecedentes del caso, se recogía la puntuación correspondiente a los criterios básicos de evaluación BI $(\mathrm{I} 3,0)$ y B2 $(4,0)-$, tras razonar que «aunque efectivamente la Comisión Nacional Evaluadora de la Actividad Investigadora goza de discrecionalidad técnica y también los Comités Asesores -no podría valorarse de otro modo el rendimiento de una labor investigadora, que además debe hacerse teniendo en cuenta de modo global el conjunto de las aportaciones por cada uno de los criterios de evaluación- no es ésta la razón que excusa, en el caso debatido, a la Comisión Nacional de exponer su juicio valorativo, aunque éste escape efectivamente al control de los Tribunales salvo casos excepcionales -los actos discrecionales deben ser siempre motivados como ha dicho reiteradamente este Tribunal y ha venido a puntualizar el art. 54.I.f) de la Ley 30/1992-, sino precisamente el haber aceptado el informe de un órgano constituido para su asesoramiento, integrado por miembros de la comunidad científica, cuya actuación se ha ajustado a las prescripciones legales dispuestas al efecto, que autorizan para traducir las valoraciones globales del conjunto de las aportaciones en una puntuación matemática referida a unos criterios de evaluación prefijados en dicha normativa», estableció la siguiente doctrina legal: «las decisiones de la Comisión Nacional Evaluadora de la Actividad Investigadora están suficientemente motivadas, aunque no manifiesten explícitamente las razones por las que valoran negativamente un período o períodos de investigación, cuando hacen suyas las puntuaciones asignadas por los Comités Asesores al valorar globalmente el conjunto de las aportaciones en cada uno de los criterios objeto de evaluación».

Así las cosas, la STS de 29 de julio de 2009 , con cita de la de I6 de marzo de 2009 , en la que se contienen, entre otras, las siguientes consideraciones: «La referida doctrina nos referimos a la STS de 5 de julio de i996- se circunscribe a los requisitos de motivación de la resolución de la CNEAI, no así a los que son exigibles a las propuestas del Comité Asesor. En este sentido, debe subrayarse que se hace imprescindible que el informe negativo del Comité Asesor esté suficientemente razonado, individualizado y concurran bases bastantes como para desestimar lo solicitado, teniendo en cuenta la relevancia de su actuación valorativa para la CNEAI. De lo contrario el art. 8.3 de la Orden de 2 de diciembre

perfeccionar dicho control jurisdiccional de la discrecionalidad técnica y definir los espacios donde puede operar con normalidad, ha completado aquellos límites tradicionales mediante la distinción, dentro de las actuaciones de valoración técnica, entre el «núcleo material de la decisión» y sus aledaños», concluye que «En consecuencia, y en estricto cumplimiento de los arts. 9.3, 24.I y I06.I de la Constitución, la revisión jurisdiccional en los casos en que concurran defectos formales sustanciales o en los que se haya dado lugar a indefensión, a arbitrariedad o a desviación de poder, el control por parte de los Tribunales de Justicia de la discrecionalidad técnica de los órganos administrativos encargados de resolver pruebas selectivas, comisiones de valoración y concursos de selección de personal al servicio de las Administraciones Públicas, tiene por objeto el enjuiciamiento de cuantas actuaciones afecten a los elementos reglados y esenciales, sin olvidar la preceptiva motivación de aquellas valoraciones, en orden a evitar situaciones ciertamente diferentes de la mencionada discrecionalidad técnica, como la arbitrariedad, la inobservancia de los principios de igualdad, mérito y capacidad y, en su caso, la desviación de poder, cuya concreta fiscalización sí corresponde realizar a este orden jurisdiccional contenciosoadministrativo». 
de 1994 entraría en franca contradicción con lo establecido en el art. 54 de la Ley 30/1992, de 26 de noviembre, del Régimen Jurídico de las Administraciones Públicas y del Procedimiento Administrativo Común, y la garantía que representa el control jurisdiccional de legalidad de la decisión decaería». ${ }^{\text {II }}$

La doctrina de los Tribunales Superiores ha tenido ocasión de pronunciarse en numerosas ocasiones en torno a actuaciones de la CNEAI, sobre la necesidad de motivación de las decisiones adoptadas por la misma, expresando con carácter reiterado la trascendencia de la omisión de este requisito por cuanto la existencia y razonabilidad del juicio valorativo, motivación o fundamentación de la decisión en cuestión pasa a constituirse en elemento esencial del control jurisdiccional de la actuación administrativa. Dichas resoluciones parten de la consideración de la motivación como auténtico elemento diferenciador entre discrecionalidad y arbitrariedad, cuya finalidad es dar a conocer a los administrados las razones de la decisión adoptada, asegurando la seriedad en la formación de la voluntad de la administración y posibilitando la impugnación por el interesado del acto administrativo de que se trata, criticando sus bases y facilitando el control jurisdiccional, resultando tan trascendente el requisito en cuestión que era obligado entender que incide en infracción formal del Ordenamiento Jurídico determinante de nulidad la Resolución administrativa que se apoya en una valoración no debidamente concretada.

Es interesante la STSJ de Castilla-León de io de abril de 20I2, que expresamente señala que «La propuesta del Comité Asesor ha de reunir una motivación suficiente, que permita al demandante conocer las razones que llevan a la Administración a desestimar la petición de valoración positiva de la actividad investigadora realizada por el demandante, lo cual es presupuesto necesario para el cumplimiento del requisito de motivación de la resolución de la Comisión Nacional Evaluadora de la Actividad Investigadora cuando, como en este caso, hace suya la puntuación asignada por el Comité Asesor.»

Las sentencias mencionadas vienen considerando que el informe del Comité Asesor que fundamenta el de la CNEAI no justifica en sus resoluciones las razones determinantes

\footnotetext{
${ }^{\text {II }}$ Esta cuestión ha sido puesta de relieve en la interpretación de diferentes Tribunales de Justicia, pudiendo citarse, entre otras, las SsTSJ de Asturias de 29 junio 2007, Canarias 30 noviembre 2005, y Galicia I8 enero y 29 marzo 2006, indicando esta última que «motivar es manifestar explícitamente las razones por las que se toma una decisión, si bien en ocasiones se admita que éstas se encuentre no en la resolución sino en el expediente administrativo; la valoración que se hace de los méritos de un concursante, en este caso de la actividad investigadora realizada durante determinado período de tiempo, mediante la asignación de una puntuación concreta, no equivale a la motivación. Eso es la decisión misma y no la motivación. Esta postura confunde claramente lo que es la motivación y lo que es la decisión del órgano administrativo. La puntuación implica en este caso decidir que la actividad investigadora no ha sido suficiente y denegar los beneficios derivados de una valoración positiva de la misma, pero no nos aporta ningún conocimiento sobre las razones por las que se valoró negativamente la actividad investigadora realizada. La motivación es un elemento fundamental para que el interesado pueda ejercer su derecho a la tutela judicial efectiva, pues sólo conociendo los motivos por los que su actividad investigadora no ha sido valorada suficientemente podrá combatirlos ante la jurisdicción contencioso- administrativa. Considerar que la exigencia de motivación se satisface meramente dando a conocer la puntuación otorgada por el Comité asesor, significa dar un paso atrás en la construcción del derecho administrativo, como un sistema de reglas y principios a los que se tiene que someter la Administración en la gestión de los intereses públicos, y en cuyo desarrollo ha tenido una contribución significativa la Jurisprudencia, colocando un grave obstáculo a la posibilidad de efectuar un control judicial eficaz de las decisiones de la Administración. Admitir que la motivación se satisface con una mera puntuación no es otra cosa que renunciar a uno de los mecanismos de control de las potestades discrecionales, cuando no directamente desistir de efectuar el control mismo de la actividad administrativa».
} 
de su evaluación, limitándose a una puntuación, sin añadir comentario alguno más, limitándose a notificar al interesado el resultado de su evaluación con unas genéricas y lacónicas cláusulas que no sirven para cubrir el requisito de la motivación tal y como ha sido definitivo, pues los términos empleados en los Acuerdos correspondientes impedían conocer al interesado y a los Tribunales la razonabilidad del juicio valorativo de la CNEAI, conculcando de este modo las normas procesales administrativas al soslayar el fundamento mismo de la decisión, impidiendo el control judicial y produciendo indefensión.

No se discute que la propuesta del Comité Asesor ha de reunir una motivación suficiente, que permita al demandante conocer las razones que llevan a la Administración a desestimar la petición de valoración positiva de la actividad investigadora realizada por el demandante, lo cual es presupuesto necesario para el cumplimiento del requisito de motivación de la resolución de la CNEAI cuando, como en este caso, hace suya la puntuación asignada por el Comité Asesor. Esta interpretación no contradice la doctrina legal establecida en la STS de 5 julio I996, y, en consecuencia, la normativa procedimental administrativa, que introduce la obligación de motivar las decisiones discrecionales y aquellas que sean restrictivas de los intereses legítimos de los administrados. La doctrina legal de la STS de 5 de julio de 1996 ha de examinarse a la luz de la evolución normativa en cuanto a la intensificación de los requisitos de motivación de las resoluciones administrativas, y de la misma evolución de la jurisprudencia, en cuanto a la expansión del control jurisdiccional sobre la discrecionalidad técnica de los órganos de selección (en este caso, de evaluación), de la cual se desprende que las modulaciones que encuentra la plenitud de conocimiento jurisdiccional sólo se justifican en una presunción de certeza o de razonabilidad de la actuación administrativa, apoyada en la especialización y la imparcialidad de los órganos establecidos para realizar la calificación, que cabe desvirtuar si se acredita la infracción o el desconocimiento del proceder razonable que se presume en el órgano calificador, bien por desviación de poder, arbitrariedad o ausencia de toda justificación del criterio adoptado, de lo que se deriva que es esencial el requisito de la motivación de la resolución del órgano de selección, en este caso evaluador de la actividad investigadora.

También siguen esta interpretación las SsTSJ de Cataluña de 2 de julio de 2008 y del TSJ de Asturias de 2I de mayo de 2009, manifestando ésta que «(e)l análisis llevado a cabo pone de manifiesto que la base la motivación de la resolución recurrida lo constituye el Informe del Comité Asesor, sin que la fundamentación ofrecida por la Comisión Nacional Evaluadora y posteriormente en la resolución del recurso de Alzada añadan otra cosa que la genérica alusión a que se han tenido en cuenta los criterios de la normativa aplicable y que se han examinado los currículos y las alegaciones del solicitante, alusiones que, en sí mismas, de ninguna manera pueden considerarse como motivación desde un punto de vista sustancial, acorde con los intereses que está llamada a desempeñar la exigencia de motivación del art. 54.I. f) de la Ley 30/I992».

En consecuencia, la cuestión a dilucidar no es otra sino pronunciarse sobre si la referencia a una puntuación asignada por una comisión de expertos cuyo asesoramiento ha recabado el órgano decisor, cumple o no las exigencias de motivación de los actos administrativos de marcado componente de discrecionalidad técnica, como es el de la valoración de la actividad investigadora en términos de «contribución al progreso del conocimiento», «innovación» y «creatividad», pues tales son los principios generales que 
han de regir la evaluación que se lleve a cabo, conforme dispone el art. 7.I a) de la Orden Ministerial de 2 de diciembre de I994, por la que se establece el procedimiento para la evaluación de la actividad investigadora.

\section{IV.9. Alcance y contenido del informe emitido por el Comité Asesor}

La Orden del Ministerio de Educación y Ciencia de 2 de diciembre de 1994 establece en su art. 8, apartado tercero, último párrafo, que «para la motivación de la resolución que dicte la CNEAI bastará con la inclusión de los informes emitidos por los Comités asesores y, en su caso, los especialistas, si los mismos hubiesen sido asumidas -sicpor la Comisión Nacional». Este precepto exime, pues, a la CNEAI, de ofrecer una motivación más exigente que la expuesta por el Comité Asesor, cuando la CNEAI se limite a asumir su criterio, lo que en definitiva no deja de ser sino una concreción de lo previsto con carácter general en el antiguo art. 89 apartado quinto de la Ley 30/1992, conforme al cual «la aceptación de informes o dictámenes servirá de motivación a la resolución cuando se incorporen al texto de la misma».

Por lo que se refiere al contenido del informe del Comité Asesor, la Orden Ministerial de 2 de diciembre de 1994 se limita a decir, en su art. 8, apartado segundo, que «el juicio técnico se expresará en términos numéricos de cero a diez, siendo preciso un mínimo de seis puntos para obtener una evaluación positiva en un tramo de seis años».

De la lectura conjunta de los arts. 8.2 y 8.3, pudiera deducirse que basta con que el Comité Asesor califique numérica y globalmente entre cero y diez la obra investigadora sometida a su consideración, sin más precisiones ni especificaciones, y que la CNEAI se adhiera a dicho informe, para que la resolución de ésta haya de considerarse suficientemente motivada.

Tal conclusión no es aceptable por cuanto de las diferentes interpretaciones posibles de los mencionados preceptos de la Orden Ministerial de 2 de diciembre de I994, ésta sería justamente la más distante con la necesidad de motivar, mediante hechos y fundamentos de derecho, los actos administrativos, lo cual se deduce también del art. 8.3, último inciso, de la Orden Ministerial.

En efecto, insistimos en que las razones de la exigencia de una motivación en las resoluciones que se dicten en el ejercicio de potestades discrecionales, incluidas las que tienen un alto grado de lo que ha venido a llamarse «discrecionalidad técnica», son, como es sabido, por un lado evitar la arbitrariedad, y por otro facilitar la fiscalización del acto, evitando toda suerte de indefensión al administrado. Pues bien, si la remisión, sin más, al informe de un comité de expertos puede satisfacer la primera de las razones, relativizando así la exigencia de motivación, lo cierto es que, tal y como está formulado dicho informe en el caso concreto del que ahora se conoce, no queda en absoluto satisfecha la segunda de las exigencias referidas: parece claro que una puntuación global referida, sin más especificaciones, a todo el currículum investigador del solicitante, no le informa suficientemente de las razones por las cuales no ha alcanzado el nivel suficiente, lo que, de un lado, le impide adecuar en lo sucesivo su trayectoria investigadora a los criterios científicos manejados por la Administración, y, por otro, le veda toda posibilidad de impugnar judicialmente el fondo de la resolución, situándolo, pues, en una situación de indefensión. 
Esta consideración de fondo debe prevalecer frente a una interpretación literalista de la Orden Ministerial, alejada de los intereses que quieren protegerse con la exigencia legal de motivación de los actos discrecionales. El art. 8.2 de la tan citada Orden dice, en efecto, que el juicio técnico del Comité Asesor «se expresará en términos numéricos de cero a diez»; pero lo que en absoluto se dice es que el "informe" del Comité Asesor, en el que puede descansar en exclusiva la motivación de la resolución de la CNEAI conforme al art. 8.3 in fine, pueda limitarse a esa expresión numérica. El número, la calificación, será la decisión final que ha de tomar el Comité Asesor, y que la CNEAI podrá refrendar (sin más explicaciones ni motivación) o no (con justificación entonces expresa), pero dicha calificación debe venir mínimamente justificada en el informe del Comité Asesor: bien asignándose puntuaciones precisas a cada uno de los trabajos y obras sometidas a consideración en el currículum abreviado presentado por el solicitante, con distinción entre los que se consideran por el Comité aportaciones ordinarias y extraordinarias, conforme a lo dispuesto en el art. 7.2 de la Orden Ministerial; o bien, cuando no se otorgue más que una puntuación global, precisando mínimamente cuáles de entre los criterios generales de calificación señalados en el art. 7.I o de los elementos valorativos referidos a lo largo del articulado de la Orden Ministerial han sido los determinantes de la calificación negativa otorgada.

Cuando tal informe se limita a ofrecer una puntación numérica global sin precisiones de ningún tipo, entonces la inclusión del mismo en el texto de la resolución de la CNEAI no satisface las mínimas exigencias de motivación, conculcándose entonces por dicha CNEAI lo dispuesto en el primer inciso del art. 8.3 de la Orden Ministerial, que la responsabiliza de «asegurar, en todo caso, la aplicación de los principios generales establecidos en el art. séptimo».

La STS de 5 de julio de 1996 se pronunció sobre el particular en diferentes términos. Pero tal doctrina se pronunció con relación a la Orden Ministerial de 5 de febrero de I990, ya derogada por la de I3 de diciembre de i993 que, a su vez, se derogó por la de 2 de diciembre de I994, aplicable al presente supuesto. No puede dejar de considerarse que en la normativa derogada, tenida en cuenta por la referida STS, se establecía con claridad que las puntuaciones que emitiera el Comité Asesor habían de referirse necesariamente de forma discriminada y pormenorizada a cada uno de los cinco criterios (dos básicos y tres complementarios) en los que podrían adscribirse las distintas aportaciones científicas o investigadoras realizadas por el solicitante y sometidas a evaluación, y que tal discriminación de criterios ya podía ser considerada, por sí misma, como una motivación suficiente, pues orientaba al solicitante sobre las razones de la valoración, positiva o negativa, finalmente obtenida.

Presupuesto lo anterior, las Sentencias mencionadas consideraron que la CNEAI no había justificado en sus Resoluciones las razones determinantes de la evaluación negativa, así como tampoco los criterios ponderados ni el contenido del informe supuestamente examinado, que ni siquiera constaba en los expedientes, limitándose a notificar al interesado el resultado de su evaluación con unas genéricas y lacónicas cláusulas que no servían para cubrir el requisito de la motivación tal y como ha sido definido, pues los términos empleados en los Acuerdos correspondientes impedían conocer al interesado y a este Tribunal «la razonabilidad del juicio valorativo de la comisión», conculcando de este 
modo la normativa procesal administrativa general, al soslayar el fundamento mismo de la decisión, impidiendo el control judicial y produciendo indefensión.

Por ello y por entender, además, que resultaba de especial trascendencia conocer el informe del correspondiente Comité Asesor como auténtico soporte de la decisión (pues su ausencia haría quebrar la razón misma del procedimiento), esta Sala acogió las pretensiones de los distintos demandantes, anulando las Resoluciones recurridas y ordenando la retroacción de las actuaciones administrativas para que la CNEAI evaluará nuevamente los tramos solicitados, motivando expresamente la decisión que adoptará conforme a los parámetros legales y reglamentarios aplicables al caso .

El criterio expuesto fue revisado por la STS de fecha 5 de julio de 1996 que, estimando un recurso de casación en interés de ley estableció su criterio respecto de las exigencias de motivación de las resoluciones de la CNEAI así como de los informes de Comités asesores. Tal criterio consiste en que «las decisiones de la CNEAI están suficientemente motivadas aunque no manifiesten explícitamente las razones por las que valoran negativamente un período o períodos de investigación, cuando hacen suyas las puntuaciones asignadas por los Comités Asesores al valorar globalmente el conjunto de las aportaciones en cada uno de los criterios objeto de evaluación».

Por otra parte, las Órdenes de 2 de diciembre de I994 y la Resolución de 26 de octubre de 1995 únicamente exigen que los comités asesores o especialistas consultados formen un juicio técnico sobre la obra aportada por el solicitante en el currículum vitae completo, siendo así que el juicio técnico se expresa en términos numéricos de o a Io puntos siendo precisos un mínimo de 6 puntos por sexenio. De tal forma que siendo precisa la emisión de un juicio general valorativo de todo el período de tiempo, se cumple con emitir tal valoración en la forma en que se ha hecho en el presente caso.

Respecto a la idoneidad de los asesores según sus áreas de especialización, la Orden ECD/2713/2003 establece en los arts. I2, I3 y I5 cómo ha de entenderse dicha idoneidad de los miembros del Comité Asesor para emitir un informe acerca de la materia específica sobre la que versan sus aportaciones.

En primer lugar el art. I2 dispone que cuando la especificidad de un área de conocimiento determinada o de la actividad investigadora sometida a evaluación lo haga aconsejable, la CNEAI podrá recabar, además, el asesoramiento de otros especialistas vinculados con esa área o actividad específica.

Esta previsión ya se encontraba en la Orden de 2 de diciembre de 1994 en la que casi con idénticas palabras se decía que «Cuando la especificidad de un área de conocimiento determinada o de la actividad investigadora a evaluar lo haga aconsejable, la CNEAI podrá recabar, además, el asesoramiento de otros especialistas vinculados con esa área o actividad específica. Las circunstancias de estos especialistas deberán ser comunicadas a los interesados a efectos de lo previsto en el número 4 de este artículo».

La Orden no introduce una exigencia superior en relación con los conocimientos de los asesores o la preceptiva intervención de especialistas en caso de que los asesores pertenezca a la concreta especialidad sobre la que versan las aportaciones, como parece sugerir el actor en su demanda. Por el contrario, el asesoramiento de especialistas se configura como una potestad de la que puede hacer uso la CNEAI cuando la especificidad 
de un área de conocimiento o de la actividad investigadora sometida a evaluación lo haga aconsejable, apreciación ésta que compete a la propia CNEAI.

Finalmente, si bien es cierto que el art. 15.3 de la Orden de 2003 dispone que el asesoramiento y la calificación que resulte de los Comités Asesores o, en su caso, de los especialistas no vincularán a la CNEAI en la emisión de un juicio técnico definitivo, también lo es que habiendo utilizado dicho Organismo la potestad de ser asesorado por un Comité Asesor también es dable que establezca la evaluación individual definitiva que debe realizar, teniendo en cuenta las calificaciones emitidas por los Comités asesores y los especialistas y con aplicación de los principios generales establecidos en el art. séptimo de la Orden de I984, y llegue a la conclusión de coincidir en la puntuación otorgada por dicho Comité.

Por lo tanto, tenor de la normativa más arriba expuesta, la valoración de la actividad docente e investigadora de los interesados se encomienda, privativamente, a la CNEAI, órgano que «podrá recabar» el asesoramiento de miembros relevantes de la comunidad científica para realizarla: (I) Los Comités Asesores se organizan y conforman «por campos científicos», término evidentemente más amplio que el de «especialidad docente o investigadora» y que permite racionalizar el asesoramiento con un número limitado de Comités. De tal forma que aceptar el argumento del recurrente sería tanto como exigir que hubiera tantos Comités Asesores como especialidades universitarias o personales existen, sistema que no han querido implantar las normas aplicables al estructurar esos órganos de asesoramiento, como se dijo, por campos científicos sin que existe exigencia respecto de la concurrencia de un catedrático especializado en la materia mencionada por el actor. (2) El Comité que correspondía a la especialidad del recurrente, como él mismo tuvo ocasión de explicitar en su instancia solicitando la evaluación, es el del campo científico o Área de Conocimiento número nueve que es precisamente el que efectúa el asesoramiento según consta en el expediente administrativo.

Merecen nuestra atención también aquellas sentencias de las que se deriva el reconocimiento de un sexenio de investigación. Ocupan un lugar destacado las sentencias que declaran el derecho del demandante a que se le reconozca la evaluación positiva de un tramo de investigación en base al resultado de las pruebas periciales practicadas durante el proceso. Sirva de ejemplo la adoptada el i8 de mayo de 200I por la Sala de lo ContenciosoAdministrativo del TSJ de Andalucía. La tarea encomendada a la CNEAI debe enmarcarse dentro de la llamada discrecionalidad técnica. La prueba pericial practicada durante el juicio llevó al TSJA al convencimiento del error en que incurrió la CNEAI al evaluar negativamente al recurrente el tramo de investigación I990-I995. La prueba es valorada positivamente por el Tribunal debido a que la misma toma en consideración los criterios de evaluación establecidos en la Resolución de 26 de octubre de I995, y entre sus conclusiones destaca que el recurrente ha mantenido durante el período evaluado una actividad y productividad científica constante con un total de 23 publicaciones $^{\mathrm{I} 2}$.

Por otra parte, hay varias sentencias que por agravio comparativo han declarado el derecho del actor a la evaluación positiva de su actividad investigadora. A este respecto puede citarse, entre otras, la STSJ de Madrid de 2I de mayo de 2002. La sentencia

\footnotetext{
${ }^{\text {I2 }}$ Seguimos, en esta parte, MARTos Martínez, G.: «La doctrina de los Tribunales sobre el procedimiento de evaluación de la actividad investigadora», Actualidad Jurídica Aranzadi 2009, núm. 766, págs. I-II
} 
fundamenta su decisión en la doctrina reflejada en la STC 62/1987, de 20 de mayo, en la que el TC afirma que junto al principio de igualdad en la Ley, de carácter material, dirigido a garantizar la identidad de trato de los iguales, existe el «principio de igualdad en la aplicación de la Ley, de carácter predominantemente formal, cuya finalidad no es que la Ley reciba siempre la misma interpretación, sino impedir que se emitan pronunciamientos arbitrarios por incurrir en desigualdad no justificada de cambio de criterio que pueda reconocerse como tal; conforme a esta concepción, la igualdad ante la Ley no constituye un mandato de igualdad absoluta que obligue en todo caso al tratamiento igual de supuestos iguales, pues ello sería contrario a la propia dinámica jurídica, una de cuyas manifestaciones es la razonable evolución en la interpretación y aplicación de la legalidad que impide conferir a los precedentes un efecto de vinculación perpetua y autoriza a un mismo órgano, administrativo o judicial, el modificar criterios anteriores, siempre que ofrezca una fundamentación suficiente y no arbitraria, obtenida a través de razonamientos objetivos y generales».

Así mismo, la STS de 26 de enero de I987 señala al respecto que «si bien es cierto que las resoluciones administrativas dictadas en un expediente no vinculan a la Administración respecto de las que han de dictarse en otros expedientes, también es cierto que sientan un precedente del que la Administración no puede apartarse más que razonando debidamente los motivos por los que no sigue el criterio anteriormente adoptado». En este marco general, el TSJ de Madrid deduce de los expedientes administrativos examinados el trato desigual y discriminatorio de que ha sido objeto el recurrente. El escrito de demanda logra su objetivo: destruir la presunción de certeza de la que goza la resolución impugnada. La sentencia pone de manifiesto que la valoración negativa es fruto de un error que vulnera el principio de igualdad, que no tolera que ante supuestos iguales se llegue a soluciones radicalmente distintas mediante, como en este caso, un error.

Otras sentencias que han tenido impacto en el procedimiento de evaluación de la actividad investigadora son aquellas que declaran el derecho del demandante al reconocimiento de un sexenio de investigación por haberse producido un error de hecho en la valoración de las aportaciones. En este sentido, puede citarse la STSJ de Cataluña de 8 de noviembre de 2005. En síntesis, el error de hecho ha sido definido por la jurisprudencia como aquel que versa sobre una realidad manifiesta, indiscutible e independiente de cualquier opinión o criterio, que se aprecia sin necesidad de invocar o aplicar disposiciones legales, de tal suerte que su sola visión pone de relieve de modo patente la comisión de un error de esta naturaleza. En este caso, el Tribunal aprecia en el expediente administrativo un error de hecho en la puntuación otorgada al período I995-2000, pues aparece en el folio I5 del expediente una calificación distinta de la obrante en el informe del Comité Asesor, folios 20 y $2 \mathrm{I}$, sin que resulte explicada la discrepancia entre una y otra puntuación. Ello lleva al TSJC a concluir que se ha producido un error de hecho en el juicio técnico realizado por el Comité Asesor, que a la postre es el que determina la resolución denegatoria del tramo de investigación, por lo que resuelve declarar el derecho del recurrente a que se le reconozca la evaluación positiva del tramo de investigación I995-2000.

Por otro lado, son muchas las sentencias que estiman en parte los recursos contencioso-administrativos. Sin duda, las que más abundan son las sentencias que anulan las resoluciones impugnadas por falta de motivación. Las mismas acuerdan que la CNEAI 
debe proceder a una nueva valoración en la que se motive suficientemente la evaluación de la actividad investigadora. Siguiendo este criterio ha sido dictada, entre otras, la STSJ de Canarias de 9 de mayo de 2005 . La sentencia declara en sus fundamentos de derecho que «la motivación es un elemento fundamental para que el interesado pueda ejercer su derecho a la tutela judicial efectiva, pues sólo conociendo los motivos por los que su actividad investigadora no ha sido valorada suficientemente podrá combatirlos ante la jurisdicción contencioso-administrativa». La motivación debe ser suficiente para que cualquier persona con sentido común pueda entender por qué las aportaciones merecen tal juicio de valor. «Admitir que la motivación se satisface con una mera puntuación no es otra cosa que renunciar a uno de los mecanismos de control de las potestades discrecionales, cuando no directamente desistir de efectuar el control de la actividad administrativa».

El TSJ de Canarias resuelve apartarse de la STS de 5 de julio de I996, que fija como doctrina legal «que las decisiones de la CNEAI están suficientemente motivadas, aunque no manifiesten explícitamente las razones por las que valoran negativamente un período o períodos de investigación, cuando hacen suyas las puntuaciones asignadas por los Comités Asesores al valorar globalmente el conjunto de las aportaciones en cada uno de los criterios de evaluación», debido a que el Tribunal Supremo se pronunció acerca de una evaluación realizada de acuerdo a lo establecido en la Orden Ministerial de 5 de febrero de I990, ya derogada por la Orden Ministerial de I3 de diciembre de i993 que, a su vez, se derogó por la Orden Ministerial de 2 de diciembre de I994, aplicable al presente supuesto. En la normativa derogada, tenida en cuenta por el Tribunal Supremo en la referida sentencia, el procedimiento de evaluación proporcionaba hasta cinco calificaciones, una por cada criterio de evaluación (dos básicos: BI y B2, tres complementarios: Ci, C2 y C3), mientras que en el caso de Canarias el nuevo procedimiento de evaluación, regulado en la Orden Ministerial de 2 de diciembre de 1994, se limita a valorar globalmente el conjunto de la obra aportada.

En cuanto a las sentencias que resuelven estimar en parte los recursos contenciosoadministrativos, también merecen nuestra atención las sentencias que han declarado nula la evaluación debido a que no había en el Comité Asesor ningún miembro cuya especialidad pudiera corresponderse con el área de conocimiento del demandante. Por todos es sabido que los científicos versados en múltiples disciplinas están desapareciendo debido a que la investigación se está especializando en todo el mundo. Los Comités Asesores son órganos colegiados formados por 5-8 investigadores (Resolución de II de diciembre de 2007, de la Dirección General de Investigación, por la que se nombra a los miembros de los diferentes Comités encargados de asesorar a la CNEAI en su labor evaluadora) que abarcan campos científicos que incluyen en ocasiones hasta 29 áreas de conocimiento distintas. La presunción de certeza o de razonabilidad de la actuación administrativa se apoya en la especialización de los órganos que deben realizar el juicio técnico.

\section{Algunas conclusiones}

La discrecionalidad técnica que rodea la actuación de la CNEAI exige que la misma cuente con el oportuno asesoramiento de miembros relevantes de la comunidad científica 
nacional e internacional cuya especialidad se corresponda con el área investigadora de los solicitantes, de conformidad con lo establecido en el art. 2.4.2 del Real Decreto Io86/i989. En esta línea, se ha pronunciado, entre otras, la STSJ de Galicia de ig de enero de 2005, que pone de manifiesto la «inadecuada composición del Comité que tomó parte en la evaluación de la recurrente debido a que no había en el Comité Asesor $n^{\circ} 5$ 'Ciencias de la Naturaleza' ningún miembro cuya especialidad se correspondiese con el área de conocimiento de la recurrente (Producción Vegetal)».

En algunas ocasiones las estimaciones parciales de los recursos contenciosoadministrativos han supuesto el reconocimiento del tramo de investigación en la fase de ejecución de sentencia. En los casos de estimación parcial los Tribunales ordenan la retroacción de las actuaciones a fin de que la CNEAI, tras recabar un nuevo informe, dicte una nueva resolución. Esa nueva evaluación se tramita cumpliendo las condiciones fijadas en la sentencia, que son muy distintas a las establecidas en la evaluación original.

Muy extenso es, como se ve, el margen para impugnar las resoluciones de la CNEAI.

Por último, la jurisprudencia también ha negado que exista indefensión. Al respecto debemos de señalar que STC I7/2009 denegó que se hubiera vulnerado al demandante de amparo su derecho a la tutela judicial efectiva sin indefensión (art. 24.I CE), en la vertiente de exigencia de motivación, en un caso igual al de autos de solicitud de evaluación positiva de su actividad investigadora a la CNEAI correspondiente a varios tramos de investigación, en el que asimismo la resolución denegatoria se basaba en considerar suficiente y hacer suyo el informe del comité asesor, que sólo calificaba numéricamente el expediente científico del solicitante, al amparo de lo establecido en los arts. 8.3 de la Orden de 2 de diciembre de 1994 y 8.3 de la Resolución de 5 de diciembre de I994, conteniendo exactamente las mismas expresiones fundamentadoras, respaldándose una sentencia del Tribunal Superior de Justicia de Madrid en la que se consideró suficiente la motivación de la resolución de la CNEAI en base a que la misma cumplía todos los requisitos exigidos por la normativa reguladora en la materia y doctrina jurisprudencial, «toda vez que: a) ha sido notificada personal y directamente al interesado, conteniendo la notificación el texto íntegro de la resolución evaluadora; y b) dicha resolución menciona la normativa aplicable, recoge la puntuación asignada a los criterios básicos y complementarios e incorpora a su propio texto el informe técnico emitido (previo examen del curriculum vitae abreviado del recurrente, dentro del contexto definido por el curriculum vitae completo) por el Comité

\footnotetext{
${ }^{13}$ Es interesante comentar en este punto la STSJ de Madrid de I3 de octubre de 200I: «I. A los efectos de la evaluación de la actividad investigadora, en el anexo II a esta Orden se enumeran los II campos científicos que permiten organizar aquella. En cada uno de ellos se señalan, con carácter indicativo las áreas de conocimiento relacionadas con uno o varios de dichos campos. 2. Corresponde a la Comisión Nacional adscribir las solicitudes a un determinado campo científico, teniendo en cuenta la conexión entre la labor aportada y los campos que figuran en el anexo II a esta Orden. Únicamente a efectos de clasificación de los expedientes los solicitantes podrán indicar el campo o campos científicos donde sugieren sea evaluada su labor investigadora. Esta indicación no vinculará al órgano evaluador para la adscripción definitiva de las solicitudes”. En el caso que nos ocupa, la demandante solicitó ser evaluada por el Comité Asesor $\mathrm{n}^{\circ} 4$ 'Ciencias Biomédicas', por entender que le correspondía éste campo científico. Sin embargo, la CNEAI estimó más adecuado adscribir la solicitud de evaluación al campo $\mathrm{n}^{\circ} 2$ 'Química'. Aunque las sugerencias realizadas por los solicitantes no son vinculantes para la CNEAI, el Tribunal Superior de Justicia de Madrid, teniendo en cuenta la actividad investigadora sometida a evaluación, llegó a la conclusión de que el Comité Asesor más idóneo para evaluar al recurrente no era el no 2 'Química' sino el no 4 'Ciencias Biomédicas'.»
} 
Asesor (...), haciendo suya la fundamentación contenida en dicho informe, que consta asimismo en el expediente, y que otorga al demandante una puntuación insuficiente (...), de acuerdo con la normativa aplicable, a efectos de obtener la evaluación positiva de la actividad investigadora del solicitante correspondiente al tramo (...), lo que determina que la resolución de la CNEAI deniegue la solicitud de evaluación positiva respecto del referido tramo». 